\title{
Thug Realism: Inhabiting Fantasy in Urban Tanzania
}

Brad Weiss

College of William and Mary, blweis@wm.edu

Follow this and additional works at: https://scholarworks.wm.edu/aspubs

Part of the Anthropology Commons

\section{Recommended Citation}

Weiss, Brad, Thug Realism: Inhabiting Fantasy in Urban Tanzania (2002). Cultural Anthropology, 17(1), 93-124.

10.1525/can.2002.17.1.93

This Article is brought to you for free and open access by the Arts and Sciences at W\&M ScholarWorks. It has been accepted for inclusion in Arts \& Sciences Articles by an authorized administrator of W\&M ScholarWorks. For more information, please contact scholarworks@wm.edu. 


\title{
Thug Realism: Inhabiting Fantasy in Urban Tanzania
}

\author{
Brad Weiss \\ College of Hilliam and Mar
}

One of the more compelling developments in contemporary sociocultural anthropology is its increasing attention to "the imagination." From the most spectacular fantasies to the most mundane reveries, imagining the world as it is and as it might be seems to be a rapidly expanding form of activity. Such imaginative acts are now held to be relevant-indeed necessary - not only to such predictable endeavors as consumption and leisure but to fields as diverse as the construction of civil society (Comaroff and Comaroff 1999a), the production of biomedical knowledge (Martin 1998), and nuclear proliferation (Gusterson 1999). This move towards all things imagined has further been characterized by an important kind of reflexivity, as exploring the complexities of "imagined communities" requires the exercise of the "ethnographic imagination." Indeed. even a cursory review of current ethnographic observations might lead us to conclude that nothing is now unimaginable.

In this article I will examine the imaginative implications of contemporary Tanzanian economy and society for a select, but by no means peripheral. group of young men living and working, mostly in barbershops, but also in other "informal" businesses in the city of Arusha, one of the largest cities in Tanzania. The expansion of this informal sector in urban Tanzania and the diverse modes of imagining that characterize it are clearly emergent under conditions of what has been described as "globalization." and it is the intersection of these rubrics-"the imaginary" and "the global"-that I intend to explore. I would suggest as a point of theoretical departure that the analytical coupling of the imagination to processes of globalization has often obscured the waly that imaginative acts are in fact materially grounded in social activities. While calls for "localization" and attention to "lived experience" have been legion, too often the act of imagining is unmoored from the specifie forms. times, and places through which persons project their possible lives. Thus. it is possible for Abu-Lughod to insist that viewers of Egyptian soap opera are "part of the same cultural worlds we inhaghit-worlds of mass media, consumption, and dispersed communities of the imagination" (Abu-Lughod 1997:128). Surcly the forms of global connectivity exemplificd by soap opera establish. or at 
least make it possible to envision, "the world" as a unified, common place (a point that will prove central to my arguments). I would suggest that the critical question for anthropological investigation is: Do we all inhabit this world in the same way? Is fantasy an assertion about universal entitlement to access a worldwide order of signs and values in a deterritorialized ecumene (lerguson 1999)? Or might its workings be most comprehensible from a grounded (if no less deterritorialized) perspective? In this article I argue that it is only when we shift our attention from ubiquitous forms of globalized imagely to the ways in which those forms are engaged that we can begin to address the articulation of diverse regional worlds and consider the production of locality as part of the constitution of the global.

Let me make it clear at the outset that I will not assert that imaginatise practice is intractably "local." Fantasy is never the mere appropriation of external signs according to the strictures of a set of transcendent, sui generis categories (Weiss n.d.). My aim is to show how the horizon of an imagined here and now, a situated "present" (Munn 1990), is made to incorporate dispersed and distant persons, values and events, and how this remote horizon is also made to encompass the here and now of urban life in Arusha. How we inhabit an imagined world, and how the process of inhabiting a world is facilitated hy imagining it, is thus the central focus of my discussion.

\section{Reviewing the Imaginary}

The years since the early 1990s have seen substantial and significant transformations in Tanzania. The extent of these upheavals might be described in the broadest of strokes. A nation-state celebrated for its one-party democracy has introduced and implemented multiparty electoral procedures. a process popularly known as mageuzi (Swahili for changes). A national press re. stricted at the beginning of this decade to two daily publications authorized $h$ : the ruling Revolutionary Party (CCM) has given way to the burgeoning production and distribution of newspapers, tabloids. comies. and magarines putlished in Tanzania. The single state radio company broadcasting from Dar $E$ Salaam in 1990, has since been supplemented by a host of state sponsored and private stations, most of them headquartered in cities beyond the capital. Until 1994 there was literally no television broadcasting of any sort in mainland Tanzania, while today the private network ITV. which is part of the IPP media conglomerate owned by Reginald Mengi, broadcasts both lecally produced serials and newscasts, as well as cast-off American sitcoms and action series. Its slogan in 1999 was: "The only station available in the whole nation!" A great many private residences and businesse's also have aceess to cable and satellite systems that offer programming from across Africil. India. Europe, and the United States. Perhaps a single iconic pronouncement conveys the force of this dizzying array of activities. In 1992. Ali Hassan Mwinyi. the second president of the United Republic of Tanzania. announced that the state had rejected the Arusha Declaration. President Julius Nyerere's renouned program of sociopolitical engineering calling for ujamaa (African socialism). In its stead. Rais 
Ruksa (President Permit), as Mwinyi came to be known, adopted the reforms of structural adjustment required by the IMF to finance Tanzania's transformation into a post-"African Socialist" society. In an astonishing bit of neoliberal synergy, postsocialist Tanzania has become the leading site within Africa for capital infusion from postapartheid South African investors (R. Schroeder, personal communication). Predictably, the "boom" of investment in the first years of this transition has given way to a massive "bust," as inflationary pressures and unemployment today escalate to levels as perilous as any in the independence era.

These wide-ranging and rapid shifts in the policy imperatives and institutional ordering of the Tanzanian state have also entailed adjustments in the structuring of its citizen's subjectivities. Consider the following exemplary setting: On a large commercial street in Arusha, in an area very near the city's largest mosque, a prominent secondary school, a reliable internet café, and the only cinema in town, sits a clean, airy barbershop (in Swahili, kinyozi) that goes by the name of Classic Hair Cutting. The staff and clientele at Classic are interested in much more than haircuts. They spend most of their time in the shop reading an assortment of daily and weekly papers, listening to music performed in French, Lingala. English, and occasionally Swahili, and watching satellite television broadcasts from the United Kingdom, South Africa, India. and the United States. The kinyozi is unmistakable from the street, its front door dominated by a larger-than-life portrait of Dennis Rodman. The social life and stylistic virtuosity of Classic evince a complex. contemporary social formation in urban Tanzania. To be sure. this particular configuration of media, technology, and labor is controlled by a relatively elite social class. but the forms and images that define this configuration are pervasive in Arusha. There are, for example, literally hundreds of harbershops in town, often more than a dozen in a single city block. Many shops are less than a hundred square feet in size, yet even the smallest must have a radio, if only to entertain idle barbers. Remarkable portrait art is a feature of even the most rudimentary shanty kinyozi, constructed from scrap lumber. Such sites in Arusha seem unambiguously to proclaim the contemporary fluorescence of popular culture as an array of practices and performances through which Tanzanians establish their place in an explicitly global and spectacular flow of images. objects. and persons. In the modes of fantasy that constitute their popular culture exemplified by such microinstitutions, urban Tanzanians imaginatively articulate and act upon a world remade.

Studies that emphasise the role of imaginative practice in social life have offered especially illuminating ethnographies of globalization.' As I see it, the prominence of the imagination. and especially fantasy, with respect to globalization needs to be understood at least at two complementary levels. To begin with. many of the tangible links through which a global order of relationships is concretized are dependent upon the dissemination of imaginative forms. Mass-mediated material imagery such as CNN reports about Balkan conflicts. advertisements that promote the pleasures of an exotic safari, syndicated African 
A merican sitcoms, militaristic action videos, or a diverse array of musical stylings (examples not chosen at random, as my discussion below reveals) are not mere "representations" of a set of global ties. Rather, the distribution of such imaginative phenomena actively constitute globalization itself. Moreover, the materiality of these images, not to mention the imaginative process itself, is worth emphasizing. The imagination is not expressed merely by means of spectacle. or entertainment. Increasingly the modes of domination that constrain flows of capital and labor and define the terms of relations between states of the North and South are themselves informed by "models" and "projections" that are products of a specific way of imagining global interactions (Carrier and Miller 1998). These examples demonstrate that the objective condition of global connectivity is, in remarkable and pervasive ways. defined as a circuit of imagery.

At a second and reciprocally related level, this global organization of imaginative forms simultaneously promotes and is itself sustained by transformations in consciousness. The subjective production of globalization entails an imaginative grasp of dispersed regions, things, and persons as part of a single place. As Foster puts it, the study of globalization must pay increasing attention to "the experiences of people living in particular localities [whose] daily existence is understood and enacted with reference to people living in other localities, indeed, understood and enacted as if all these people lived in one place at the same time" (Foster 1999:140). This latter feature of prevailing circuits of global interconnection is fundamental to the processes and practices I will be assessing in this article. Recognizing that Tanzanians-especially the sporadically employed young men in this precarious urban context-envision and act upon such an imagined "global totality" will allow us better to appreciate the changing character of contemporary sociality. Many have also argued that it is not only the case that a global imagination imagines a global totality, but that globalization seems somehow to engender imagining as a routinized activity. From this perspective, much of daily life under conditions informed by the global circulation of images and situated in the purview of a common world is now dedicated to-or predicated on-an active imagination. As Appadurai has succinctly put it, in a widely cited and apt phrase. "fantasy is now a social practice" (1991:198). In this epochal view of current social transformations (a vicw that I will interrogate further), lived worlds distinctly situated as they may be throughout the globalized world are increasingly constructed through fantasies and fabrications that inust first be imagined in order to be realized.

There are any number of insights that this innovative concern with fantasy and the imagination may offer, many of which guide the ethnographic analysis I offer helow. One especially salutary aspect of much recent literature is its refusal to separate "imagination" from "reality" because such an opposition between "fact" and "fantasy" is unsupportable. If fantasy in now a social practice, it follows that fabrications are social facts. Acts of the imagination are. indeed, most evident in the varied modes of "realism" they generate (Appadurai 1991). Far from (simply) an indulgence in escapist and illusory delusions. 
imaginative practice becomes essential to the very definition of reality as it is perceived and encountered. Conceived of in this way, fantasy becomes a medium through which to pursue the concrete processes by which consciousness is engaged in the world. A further insistence of many who address the imagination is the recognition that such practices include far more than liberatory exercises in boundless, cultural creativity. Our interests in the imagination must incorporate the fantasies of ethnic cleansing and other brutalities as well as educational aspirations, regimes of mass consumption as well as utopian visions of democratic reform (Appadurai 1991; Foster 1999). These cautionary reminders about the potential of fantasy and the "possible lives" at stake will all prove relevant in my discussion of the dreams and frustrations characteristic of street life in Arusha.

Such are the merits of much contemporary attention to fantasy. And as my discussion will make clear, I consider the phenomena of imaginative fantasy to be absolutely essential to the expression of popular culture in Arusha and elsewhere. At the same time, I would also argue that there are some important premises that advocates of an imaginative approach to social life leave largely unexamined. My purpose here is not so much to critique these premises as it is to elucidate them as carefully as possible and to try to be specific about how they might enter into an ethnographic account of popular cultural practices. Is it really the case, for example, that the world is now a more imaginative place than it was during some putatively image-free earlier period? Have tradition and the "inertia" of habitus given way to the "innovation" of imagining under contemporary conditions of globalization? Appadurai invokes an explicit contrast between a taken for granted, "givenness" of existence that is now being challenged by ever more widespread exposure to alternative "possible" lives (1991:198). Such a division, in my view, runs the risk of reinstantiating a division between "closed" and "open" societies, now arranged as distinct historical moments, rather than divergent, contemporaneous world views. Of course, it must be pointed out that in spite of this apparent fascination with the newest new thing, attention to the imagination has scrupulously avoided teleological pronouncements. No one is suggesting that the trajectory of possible futures is already known, nor can we predict the forms and relations into which contemporary fantasies may enter. Overgeneralizations that take this comparative form are useful, if only to alert us to a pervasive practice that has largely gone unnoticed. So, while I am wary of dichotomies between "givenness" and "possibility," I am certainly willing to concede that something is distinctive about the world today. As I have already indicated, in the popular cultural practices of young Tanzanians the proliferation of contemporary modes of fantasy is an unmistakable empirical actuality. Profound and enduring relations have been forged in the medium of fantasy and a diaspora of images is every where in evidence. Further, these images are not just empiricaly present in ways not previously possible (especially given the significant limitations on mass-mediated forms available in Tanzania until quite recently), they are socially salient, drawing intense interest and serving as models of and for reality. Still, it is not 
entirely clear that this irrepressible imaginative activity is now essential to sociocultural life in ways that it never has been before. As Comaroff and Comaroff suggest, "global flows" present "a problem of scale":

The processes involved in the rise of novel forms of planetary integration and compression-especially in the electronic economy, in mass communications, in flexitime flows of labor and capital, in the instantaneous circulation of signs and images, in the translocal commodification of culture, in the diasporic politics of identity-challenge us by representing the most fundamental question of our craft: how do human beings construct their intimate. everyday life-worlds at the shifting intersections of here, there, elsewhere, everywhere. [1999b:295]

Globalization from this perspective is characterized by a distinctive range and articulation of relations, places, values, and persons-distinct principally because of the innovative, proliferating media of "compression" that facilitate the widespread sense of a "global totality" to which I have alluded. But the "shifting intersections of here, there, elsewhere, everywhere" are an enduring feature of sociality and of social analysis in general, not an unprecedented possibility ushered in by globalization itself. The range of "possible lives" and the accelerated pace with which such possibilities present themselves seem distinctly different today, but even habitus requires imaginative activity if it is to be more than mindless repetition. ${ }^{2}$ Indeed, it may be useful to theorize, not the passage of a "habitual" mode of being into an "imaginative" one. but the intrinsic connection between these alternatives. This is a connection-the structuring structures of fantasy we might say-that I hope to demonstrate here.

I am persuaded, as I have said, that imaginative practice is a central, dynamic feature of social life in much of the world. How can we account for this centrality? I would argue that for many theorists, fantasy and the imagination have seized social purchase, not just by means of globalization, but through a profound process of rupture-of disjuncture, dispersal, (perhaps even distortion) and most especially deterritorialization. If we follow the implications of these presumptions of rupture we might be lead to argue that imaginative connections were required to restore - albeit in an entirely invented fashion-once present solidarities. The taken-for-granted, this argument goes, gives way under conditions of deterritorialization (described by Appadurai [1991:193] as "the loosening of bonds between people, wealth, and territories"). such that the immediacy of social life can only be sustained with imaginative effort. Hence. the medium of print capitalism classically fosters "imagined" national honds (Anderson 1983), or Bollywood films promote a diasporic Hindu fundamentalism (Appadurai 1991). To be sure, these imaginative supplements of a deterritorialized world do not simply replace the honds of a "territorialised" one; enlightened nationalism is hot identical to fealty to the Church; and BJP (Bharatiya Janata Party) fantasies may scarcely resemble the Hindu tradition they defend. These imagined realisms are certainly innovations, but are they driven by the functional demands of displacement? Are fantasy and imagination the "new needs" of a global ecumene? Aside from these functionalist indications. 
there is also the suggestion that to the extent that imaginative practice is novel, it supplements something previously less imagined-hence somehow more concrete and substantial. One might then conclude that while "fantasy" is no less real than "reality," there are "realities" that are more tangible than some or, conversely, some are more ethereal than others.

My dissatisfaction with what I take to be these instrumentalist premises of our "newly" imaginative age is less a refutation of the impetus to investigate fantasy, than it is an uneasiness with the fit between the imaginative practices now under consideration and the broader contexts in which they play an (irrefutably) central part. For me this raises crucial questions about what we take to be imaginative practice and how we attempt to make sense of it. What, for example, is the status of the term imagination or the imagination? Is this a descriptive category or an analytical construct? Does the "imaginative turn" in anthropology merely reflect the empirical content of a new world order, or does it demand new conceptual forms with which to comprehend the character of social life itself?

Certainly the force with which social theorists now promulgate their interests in the imagination suggests that more than just the "stuff" of life has changed, but so must the terms by which we engage it. In particular, a focus on the imagination has been offered as a counter to the shortcomings of the culture concept (Abu-Lughod 1997; Appadurai 1996; Bayart 1996). Today it is de rigueur to describe a "global imaginary," but hopelessly retrograde to speak of "culture" in globalization. But can this distinction tell us how "fantasies" differ from "cosmologies?" Just how are "imaginative" phenomena different from "cultural" ones? For a great many, the term culture invokes assertions of "timelessness," "coherence," "unity," and "boundedness," and so distorts the fluid and contradictory character of human experience. The imagination, then, is explicitly posed as a mode of recognizing the priority of instability and uncertainty. "The imaginary," says Bayart, "is by definition the domain of ambivalence" (1996:166). With due attention to the imaginary, Appadurai tells us, "Culture ... shifts from being some sort of inert local substance to being a rather more volatile form of difference" (1991:295).

I am entirely in sympathy with this antisubstantialist understanding of human activity. Moreover I recognize that the term culture-especially given the identity politics of "encyclopedic multiculturalism" (Turner 1993)-has come to play a critical role in some of the more disturbing social movements of our time. Whether anthropologists describing "political economies," "discourses," "regimes," or "imaginaries" will improve the plight of those embroiled in "cultural conflicts" is open to debate. What is more, I would agree with Sahlins when he insists that critiques of culture opposed to claims of "timelessness," "coherence," "unity," and "boundedness" (this is Sahlins's litany) rail against a wrongheaded notion of culture that never was (1999:402). In any case, I do not claim to be able to resolve ongoing debates about the value of culture; I am more interested in understanding how fantasy works. For any people to imagine fantastical worlds, these fantasies must first of all be meaningful to themselves 
and meaningful to those with whom they elaborate, share, and contest their visions-an assertion that nonetheless divulges where my sympathies lic in these culture debates. As my arguments will make plain, I take globalization seriously and understand the lives of young men and women in Arusha 10 be organized by complex, fluid, and translocal circuits-and even processes of rupture. I would argue, though, that a focus on grounded and embodied practice will allow us to think about how a particular world and its relevant component places are imagined and what the values are that give that synthetic world coherence and allow its dreams-and certainly its nightmares-to be sustained, concretized, and enacted in the course of social interaction.

\section{From California to Kosovo: Fantastic Geographies}

If inhabiting the imagination is the core process under examination, why am I looking in barbershops? The best answer I can give to that question is to pose another question: Why have barbershops been chosen by Arusha's young men? We know that not all global flows flow equally. "The network of flows is not fixed; nor is it symmetrical. There are blockages: not everything flows everywhere in all directions" (Hannerz 1996). Therefore, we might ask why some of these flows are so intensified and marked in the milieu of the kinyozi. As I indicated above and have discussed at length elsewhere (Weiss n.d.), there are literally hundreds of vinyozi (plural of kinyozi) in and around the cil! of Arusha. They line the tarmac from Morogoro to Nairobi, and each of the tracks leading up from this main artery into residential areas has more than a few barbershops. Not only Arusha, but other towns in Tanzania, taking their lead (according to folk theories of barbering) from trend setting Dar es Salaam. also known as Bongo (after the Swahili term for brain), ${ }^{3}$ have seen a substantial increase in vinyozi. In brief, the explosion of these cosmetological enterprises can be linked to the political-economic restructurings to which I alluded earlier. The constraints of structural adjustment in Tanzania, and especially in urban Tanzania, precipitated a dual move, one that is increasingly commonplace under global neoliberal regimes. Tanzanian society was simultaneously "opened" to media, goods, and ideologies never before available, while the decline of state services and subsidies has led (after a brief flourishing of both the formal and informal privatized economy) to the collapse of a host of employment opportunities. This sudden crash on the heels of unprecedented and exhilarating possibilities-unrealized by the vast majority of Tanzanians as any. thing but possibilities-made it possible for a broad swath of people to desire the signs and styles of a global order, while facing ever narrower means hy which to satisfy them.

This widening breach between the actual and the possible has been forged by harbershops in Arusha. In their own accounts, the young men who work in and frequent Arusha's vinyozi make direct references to the historical character of these businesses; and the same is true, in this thoroughly segregated commercial niche, for the women in Arusha's "saloon." and beauty shops. As many barbers and clients told me, harbershops are a new social institution. 
plainly a part of the contemporary Tanzanian landscape. While people have long been tending to their hair, barbershops are "things of today," (mambo va siku hizi) and unknown to "elders from the past" (wazee wa zamani). Some told me that barbershops were part of the changes that had been brought about in the last five years in Arusha and were explicitly created "for the sake of the youth" (kwa ajili ya vijana). The vinyozi are appropriate for the youth because they are especially interested in the forms and fashions that circulate through this microinstitution, but also because vinyozi provide young men in times of tumult and uncertainty with a "chance," an "opportunity," or a "place" (all indexed by the Swahili term nafasi)."

For urbanites young and old in Arusha, barbershops are a tangible index of the fact that the world has changed. I want to focus here on the fact that this tangible character is most readily grasped in the way that barbershops reconfigure "place" - not only in Arusha itself but the place of Arusha in the world. While I am not persuaded that this imaginative reorganization of and dwelling in space is entirely determined by the forms of rupture and detcritorialization to which East Africans have been subjected, neither would I wish to dismiss the reality of processes of displacement in urban Tanzania. The city of Arusha in Northern Tanzania is constituted by an internal East African diaspora. Celcbrated in the nearly completely obliterated history of African socialism as the site of Nyerere's Arusha Declaration and the capital of the erstwhile East African Union, Arusha is now a thoroughly global cosmopolis. It is home to both the International War Crimes Tribunal on Rwanda and the current peace talks on Burundi, as well as the gateway to the Serengeti and Kilimanjaro. It abounds with U.N. representatives and tourists that range from the backpacking masses to the Abercrombie and Kent coterie. It is also a burgeoning. socially complex. interethnic town. Commercial enterprise is still largely dominated by a prosperous Asian community (Rona Peligal, personal communication. June 1999): a rift between Pentcostal and Lutheran dioceses has torn Christian communities apart in recent years (Baroin 1996). While WaArusha and WaMeru are the predominant peoples that reside on the farms ascending Mount Meru. Arusha itself is a town of relative newcomers from virtually every region in Tan zania with especially large communities that retain ties to the Coast (from Dar es Salaam to Tanga). Tabora to the Southwest, and Kilimanjaro and the Pare mountains to the liast. The lives and practices of Arusha s residents are shaped by any number of imaginative links to "clsewheres" near and far. Localities within Tanzania, like pwani (the coast) and porini (the bush) are well established as icons of such characteristic forms of identity as Muslim orthodoxy, or traditional "Maasal" indigeneity. Movements across Tanzania's border also figure prominently in these links. In addition to their reception of mass-mediated forms of entertainment from abroad. Tanzanians in Aruha are also cognizant of growing connections with the Persian Gulf. as an influx of Iranian, Saudi, and Kuwaiti funds in recent years has promoted literacy and educational programs, as well as Shite sectarian practice and nosque construction. Growing ties of kinship to the Arab world. in particular. have further enabled the circulation 
of an array of consumer goods, from VCRs and videos to textiles and medicines. Increasingly, Tanzanians have hegun to imagine the "possible lives" that might be available within Africa, but beyond East Africa. Bondeni (Swahili for in the valleys, or down below), as South Africa is now known in the vernacular, is an emerging magnet for a growing number of the men and women I spoke with in Arusha.

These expanding interconnections have not only helped to detail a vision of the world "out there," they have reciprocally promoted an awareness of Tan $/ a$ nia as a place within this nexus of places. For most of the residents of Arusha. this is a profoundly troubling scene. As is now commonplace across the continent (Ferguson 1999), most Tanzanians I know are convinced that life is better elsewhere and that the grind of struggle and poverty, of kutafuta maisha (looking for a life), is immeasurably eased anywhere but here. Tanzanians, as Stambach has pointed out, have developed a political culture "in which citizens minutely inspect themselves and others" (1999:252). This self-scrutiny, in particular, is heavily moralized in present day Tanzania, especially with respect to emerging understandings of Tanzania's unfortunate place in a wider world. Thus, a common theme in the "national imaginary" of the current moment focuses on Tanzania's own failings as a nation-failings of both leadership and citizenry alike. The refrain of a WestSide-flavored rap by the best-selling rap artists Hard Blasterz Crew puts it this way:

Tuko nyuma kimaendeleo

Sababu ya rusho,

Udhaifulifu na upendeleo.

Tuko nyuma (Mpaka lini?)
We're behind in development

Because of being thrown aside.

Weakness and favoritism.

We're behind (Until when?)

Claims such as these, which pick up on conversations and complaints that could not be more ordinary and pervasive, explicitly characterize Tanzania's condition with respect to an image and discourse of global integration, namely development. This imagery plainly reveals a sense of marginality, but it is a marginality that follows from both expulsion and inadequacy. For many in Arusha, the "weakness and favoritism" described are felt not only to be perpetrated upon Tanzanians, but they are more likely to hold themselves accountable for these very shortcomings.

This sense of expulsion and inadequacy is literally built into the urban landscape fabricated by the mushrooming growth of barbershops. These shops, more than any other local businesses, self-consciously reference a global order as it is articulated in Arusha. Consider the names of these shops. already briefly mentioned. Barbershop names are almost always derived from English: Classic Hair Cutting, Boyz II Men, 2J Barberhouse. In this they are not substantially different from other shops and kiosks in Arusha's city center. What is distinctive is the way these shops commonly name themselves after particular places, none of which can be found within Tanzania. There are a Brooklyn Barberhouse, a Queens (named after the New York City horough) Cutting Shop, a Liverpool Barbers, a Paris Cuts, and more than a docen variations on California Hair Cutting (Figure 1). Kinshasa Barher House and the brand new 
Cape Town Barbers give evidence of the prominence of these locales as desirable places abroad. Even Kosovo and Death Row (the record label, not the penal status) are lionized in paint and iconography. Yet there are no Serengeti Saloons, no Kilimanjaro Kuts, in spite of the fact that most young Tanzanians know that these are places known beyond the borders of the nation. Fven Dar es Salaam, renowned in Arusha as the place to be in Tanzania, is denied harbershop veneration. The use of English names that refer to an international array of locales is by no means an exclusive characteristic of barbershops. Bars and restaurants, salons and pharmacies, as well as a host of other formal and infor mal businesses have similar names. My argument is that barbershops are a kind of apotheosis of this tendency, pervasively representing "other" places

What seems paramount in these forms of self-promotion is not just their glorification of celebrity and seduction but the kinds of distancing that they both create and depend upon. This simultaneous aggrandizement and disaffec tion might further account for some of the more curious and arresting features of Arusha's fantastic geographies. A great many young men and women in Arusha are, for example, devoted followers of gangsta rap (Remes 1999: Weiss n.d.) and closely follow the tabloid stories, widely published in hoth Swahili and English in Tanzanian and Kenyan papers, that detail the careers and feats of any number of American thugs (wahumi). Wahumi has become widespread in the vernacular as a self-description. All such devotees recognize that the hardeore

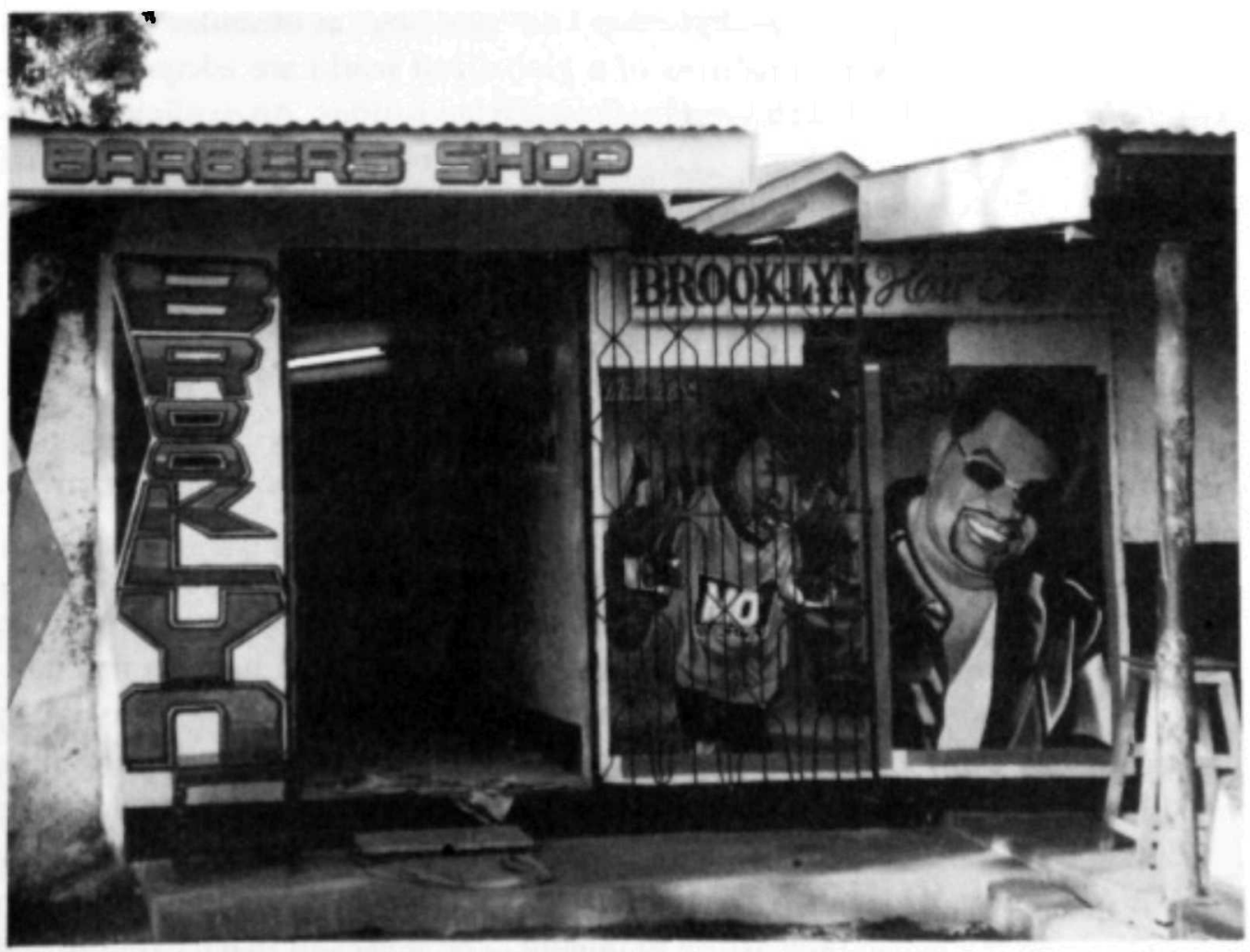

Figure 1

Brooklyn Haircut. 
gangsta world is predominantly divided into two competing camps-East Coast and West Coast. Every aficionado I asked stated a strong preference for West Coast rap, a style that is self-described (by Californian rappers and their Tanzanian followers alike) as harder (gumu), and fiercer (kali) than that of their New York-New Jersey counterparts-players who, as one friend of mine put it, "only know money." Indeed, the first time I discussed this regional difference in Arusha I was told that the West Side was where blacks lived, while whites lived in the East. In spite of this clear set of affinities and detailed understanding of remote regional differences, every barbershop displays an aggressively eclectic range of images that praises East and West Coast alike. Death Row Barber House (or one of many so named that I visited every day) named for the record label founded by Tupac Shakur (along with producer Suge Knight), perhaps the most prominent gangsta martyr and icon of the West Coast sound, is also painted with an enormous icon of $\mathrm{Mr}$. Cheeks, a member of the Lost Boyz from Queens, and divides its wall space fairly evenly between pasted up cutouts of East Coast players (especially Lost Boyz, Puff Daddy, Mace, and Notorious B.I.G.) and West Coast (Tupac, Dr. Dre, EZ.E and Snoop). Mixtures like these, typical of Arusha's barbershops, are telling illustrations of a worldview. It is certainly the case that young men in Arusha have limited means and paper their shops with photos from whatever magazines are at hand. But these material limitations are not sufficient to account for the $\mathbf{s}$ ! listic choices that are made or the clashing conjunctions that are fabricated. Nor do I think that appeals to "hybridity" or "pastiche" as attitudes that flourish in the popular cultural practices of a globalized world are adequate to account for the order that is achieved by these juxtapositions. An explicit invociation of conflict and violence is achieved by conflating these adicrsarial images-small wonder that "Kosovo" was stitched into wool caps. tagged in graffiti across construction sites, and plastered on minivan transports across Arusha in the Summer of $1999 . .^{5}$ When I tried to purchase a Kosovo cap, the twelve-year-old selling them on the street told me people had quit making them. "Buy the NATO," he said, "NATO is the fierce one!" This conflict, as I aim to demonstrate below, synthesizes these disparate clements into a coherent, if intrinsically tenuous and fitful, totality - a whole world distinguished by its enduring and indomitable struggle.

But note again that in creating this geographic synthesis via juxtaposition. the places and personages of Arusha, and indeed Tanzania, are nowhere to be found. East Coast and West Coast can and must he combined in ways that conflate the loci of a wider world within a common horizon. One kinyor in Arusha's bus stand is called Las Vegas, California, so named by young men who knew very well the differences between them. This horizon, however. is firmly elsewhere. It is as though in naming and publicizing the places they regularly occupy, Arusha's harbers reflexively display and proclaim their own absence from the world they aspire to inhabit. The senses of place exemplified by these harbershop motifs give evidence, I would argue. of what Comaroff and Comaroff have characterized as "startling similarities in the current situation 
of youth the world over," a situation founded on "a doubling, on simultaneous inclusion and exclusion" (2000:307). The habitués of these vinyozi plainly assert a profound command of place, celebrating the spectacular and demonstrating their nuanced grasp of a cosmopolitan spatial order, remaking the strects they inhabit in the image of the topoi they admire. Yet, even as they evince these creative powers, they seem to exclude themselves as knowing subjects of the world, as subjects who reside in localities that they purposefully do not recognize. Elsewhere I have described this simultaneous inclusion and exclusion. command and subjugation, in terms of a process of subjectification through which Arusha's young men deploy their own subjugation (articulated most commonly as "pain") as a means of overcoming their marginalization (Weiss n.d.). What I want to describe here are the ways in which this dialectic. and especially the forms of distancing constituted by it, provide a possible avenue for understanding how young men in Arusha (and perhaps the world over) ground themselves, and thereby come to belong to an imagined configuration of space and time. ${ }^{6}$ Clearly the fantastical barbering landscape incorporates innumerable "others" and "elsew heres" as critical landmarks: but how. then, is it possible to reside in a "here and now" remade into a distant horizon". Is this transposition of localities simply symptomatic of deterritorialization: the "erosion of the cultural distinctiveness of places" and a "generalized sense of homelessness"(Gupta and Ferguson 1997:35-37)? Or might the specificity of the se particular places, troubled and unsettling as they clearly are. conflated and transposed to the streets of Tanzania's urban secene, suggest that Arusha's young men have found ways to inhabit the processes of their own displacement?

\section{Thug Realism}

In order to address these problems of how the particular spatial and temporal manifold of "the present" is inhabited in Arusha. it is important to reconsider the harbershop within a somewhat different theoretical framework. Thus far I have addressed these shops as locations, that is. as places arrayed as a topographical network across the urban setting. As places these shops exhihit a rather remarkable stylistic consistency, although they are certainly not uniform in either their appearance or their services. ' Beyond the circuit of images that establish vinyori as interconnected locations. there are material and economic forces that shape the lives of the shops and those that occupy them. Some barbershops are hewn from scrap lumber and ceiling board: others occupy space rented from municipally owned offices and residential buildings. Yet. almost every kinyozi occupies a precarious zone. Successful shops generally rely for support on prominent patrons who are almost always bound by ties of kinship to some of the harbers employed. These patrons are occasionally civil servants with modest resources available for redistribution. and more often patrons are watu binafsi (businessmen) engaged in small-scale enterprises (e.g.. importing clothing, or spare parts, or small electronic appliances from kenya. Dubai, India, Canada, etc.) who see the vinyom both as a rather cheap means to strengthen kin and affinal ties. expand a range of clients available to support their commercial 
schemes, and occasionally use as venues to market the wares (e.g., videos. shoes, cosmetics) of their other businesses. The dependence of villyozi on more powerful patrons, who are themselves connected to uncertain and shifting movements of capital (especially under the current terms of structural adjustment), highlights the insecurity of these enterprises. A shortage of clients, or a lack of patronage may make it impossible to pay rents or utilities. therehy suddenly closing down businesses that once seemed to thrive. $2 \mathrm{Buy}>\mathrm{Hair}$ Cut did a pretty good business as a shanty construction, drawing electricity off the residential building to which it was attached. It was busy enough to atford a new iconic painting of Kofi Annan for its front door in 2000, until one Friday evening, after failing to pay its rent and utilities for a few months, 2Boy's was literally pulled to pieces by the landlord whose building the shop abutted. The example is dramatic, but hardly unusual. Further, the unstable sector of Arusha occupied by vinyozi is crosscut by a host of other kinds of places that are equally tenuous: shoeshine stands, the open-air sewing machines of seamstresses and tailors, and fruit and vegetable sellers along the sidewalk. Processes of displacement are thus readily apparent throughout the town and never far from the thoughts of those who occupy these places.

Considering these shops only as "places" in this way however objectifies them as zones or maps that are characterized by a certain terrain. In this case, the imagery of popular global locations-Brooklyn, Liverpool, Kosovo-e'stablishes critical cardinal directions on this map, points of orientation that $\cdots$ ablish the position of the "present" in Arusha. The interconnectedness of these positions as external places conflated on this urban scene creates a certain image of the world and of Tanzania's place in it (or outside of it. as the case ma! be). These points of orientation are important for indicating imagined boundaries and links in the world and for suggesting forms of transposition and global interconnection. Understood in this way, Arusha's barbershops constitute what Lefebvre calls "Representational Spaces, embodying complex symbolism. sometimes coded, sometimes not, linked to the underground side of social life" (1991:33). Nonetheless, this way of approaching barbershops as representational spaces, or as a set (or even system) of places needs to be complemented by a consideration of popular practice in Arusha as a spatial field of action. The image of the world displayed by barbershop names and décor represents a particular locale in which activities take place. In my view, this objective representation or image is only the product of what Munn (1996:451). following I.efebvre (1991), calls a "mobile spatial field." Within this framework. space (including places like barbershops) is not the "setting" or the "container" of activity, it is rather ongoing social activity which has, and so concretizes. a spatial form. Social practice, in other words, defines a spatial world. its "boundaries and directions ... lines of force, [and] perspectives" (Merleau-Ponty 1962:112). When we situate problems of imaginative practice within this model of spatiality we can hegin to ask different kinds of questions. My aim in this section is to ask: How does social practice in Arusha define the kinyori as a frame of action which permits the articulation of the distanced places, persons. 
and things-already described as a horizon for this "present"-within a field of lived practice? How, in other words, do the popular practices that bring barbershops to life in social experience constitute the global as an aspect of the local and thereby produce locality as an intrinsically global reality? When we consider how the space of the barbershop incorporates lived spatiality, including especially the lived spatiality of the body, we have a basis for grasping both how barbers and their clients bring the world into the shop, and how they project the shops as distinctive features of this world.

The activity in and around a barbershop, to which I alluded above, includes much more than getting a shave and a haircut. Barbershops in Arusha are hubs for the dissemination of a variety of media: radio and television broadcasts, as well as the circulation of daily and weekly papers and magazines. They are also central nodes in the public presentation of self; that is, a wide range of personal grooming and appearance activities (e.g., selling used clothing door-to-door, shining shoes, tailoring outfits) are brought to the barbershop. A barbershop is (in part) a venue in which both to create a display and to display one's self. ${ }^{8}$ As I have described elsewhere (Weiss n.d.), the kinyozi both asserts itself into the street life (mtaani, or kitaani) of Arusha, and simultaneously enfolds the street into itself. Barbers and clients call out to passersby from the open interior or the immediate front of the shop; when folks in the street enter the social field of the shop, they make their presence felt by carefully shaking hands and greeting everyone assembled at the kinyozi-gestures that must be repeated in reverse when anyone takes his leave. In all these ways, the barbershop is a gathering place, a pivot for the mobile dispersal of persons and things, a social field created by an active "coming together" of forces, that also anticipates a continuous circulation outward from within. In this respect, the kinyozi is less like a house in which people reside, leaving and returning during the course of the day, than it is akin to the street itself-both a recognizable place and a medium of traffic and movement.

These social qualities are explicitly recognized and commented upon by the denizens of vinyozi. Indeed, it is common to hear a barbershop described as kijiwe (the little stone). This diminutive term draws an immediate parallel to rural locales and connotes a fixed place-a stone for gathering in conversation and greeting. It epitomizes a place at which bonds of intimacy are publicly forged and enacted, created and made known to others in the community. The recognition of the barbershop kijiwe as a dynamic place within a field of activity is also complemented by the way it organizes social bonds. Amid the coming and going, with handshakes constituting and demonstrating the contours of the space, people will often greet those gathered at a barbershop, if only to say that they cannot stop to chat or that they will return later. "Nipo "round" (I'm around), they will tell their friends. This greeting has a locative form (-po) that connotes an immediate area that circumscribes the shop, and it further refers to the movement of the person that establishes this circumscribed area (which includes the kinyozi) by their act of making the 'rounds (kupiga 'round). By these actions in language and motion, the barbershop is created as the stone, 
the solid gathering place in the midst of (and so a part of) the dynamic circulations of social life.

These innocuous features of spatial practice in Arusha may seem unremarkable, although they are directly invoked whenever young men gather and greet or take leave of one another at a shop. When we put this practice in a broader context, we will see that this specific spatial field reveals a good deal about the sociality embedded in it. Kijiwe, for example, is not simply a little stone and therefore a metonymic extrapolation from a rural idyll. In fact, the term kijive itself has multiple referents; and this multiplicity reveals a great deal about the way the space of the "public sphere" is gendered in an urban localc. To begin with the kijiwe in many Tanzanian villages is the grindstone, a place where social ties are forged in the course of often grueling, physical labor. This concern with the demands of strenuous activity is directly linked to most young men's characterization of their own lives on Arusha's streets. The grindstone, moreover, epitomizes central quali-signs of social interaction for many of these young men. The kijiwe is solid and enduring: it is a form that "survives" (a vernacular term that denotes persevering through struggle). By its very nature a kijiwe is hard, a quality much admired and absolutely necessary in this milieu. The grinding activity of the stone is likened to the conflict that needs to be confronted and worked through in daily life. Calling a harbershop kijiwe suggests that it is a place of work and so a site of struggle. This struggle is further in evidence in the very terms that a great many young men in Arusha use to describe themselves: Wahuni (thugs) is a term widely adopted in global hip-hop expression. These are both terms that carry enormous negative implications. Muhuni (singular form of wahuni) has become a central term in contemporary Northern Tanzanian moral discourses about reprehensible character and behavior (Setel 2000 and Stambach 2000), and the self-designation as a muhuni (or thug in Tanzania and elsewhere) is plainly a way of inviling scorn and thus showing one's toughness in a world of confrontation. These practical understandings indicate that the fantasy space of kijiwe is not a convivial respite from hardship. but that even the pleasures of conversation are framed by hardship.

As a "hard" place of hard work, kijiwe captures central aspects of a social world imagined and admired by many young men in Arusha. Equally central to the fantasies of struggle and endurance sustained by allusions to the grindstone is what is (purposefully) occluded by this transposition of the rural kijiwe to the urban kinyozi: and that is. quite simply, women. For wherever there are grindstones in rural Tanzania, it is women who carry out the grinding there. turning grain into flour in preparation for porridge or beer. Even young unmarried men, such as those that hang out in barbershops, would not be expected to carry out this kind of food-provisioning activity. How might we account for this gendering of the barbershop? To begin with, we might note that such appropriations of cross-gender practice, for both men and women, have long been characteristic of rites of passage essential to the formation of gendered persons across East and southern Africa (Beidelman 1997; Comaroff 1985; Turner 
1967). In this way, initiation works to conflate gender identities. defining a liminal being whose ambiguity must be worked through in the embodiment of mature gendered personhood. But what is especially pronounced in men's rites are the ways that the embodiment of mature masculinity is held to depend upon the appropriation of femininity in order to dominate a powerful creative force which otherwise escapes masculine control (see, e.g.. the Ndembu tale of the origins of circumcision, Turner 1967:152-153). While I do not think that the barbershop as a social institution can simply be read as a direct urban translation of rural or regional initiation rites (although I would not dismiss this association either), I do think that the gender dynamic of appropriation, as a means of domination often at work in initiation, is quite relevant to the social world of these young men. It is surely no accident that Arusha's barhershops, which take their colloquial name from rural sites of female work, are urban places and places of work where women never work. ${ }^{9}$ In my view. identifying the urban shop with the signifiers of the rural grindstone asserts a parallel between these locales that draws explicit attention to the fact that barbershops are placis from which women's work is excluded. In effect, this gendering of the barbershop is an appropriation of women's activity which instantiates a gender asymmetry.

At the same time, an alternative rural referent for kijiwe is widely recognized in town. In the Meru and Chagga villages densely settled across Mount Kilimanjaro and Mount Meru, ${ }^{10}$ kijiwe can also refer to the hard stone altars at which clan sacrifices are offered. "Like grindstones, these sites are also points of gathering and conversation; but unlike grindstones. these altars are especially associated with masculine actions. Bloodshed and violence are harnessed by senior men for collective ends at sacrificial altars. In this way. these kijiwe are characterized by distinct temporal rhythms: on a daily basis these stones are the site of conversation and a sociality that is iconically represented by the punctuated acts of sacrifice. The sacrificial kijiwe, then. is constituted by hierarchical relations in which the ebb and flow of daily conversation is embedded in a place intrinsically bound up with the masculine authority of clan elders and the danger of bloodshed.

When we situate these rural gendered meanings and practices in the context of urban life, a further dynamic in sociality can be explored. Barbershops are not only metaphorically grindstones and altars, they can also be described as baraza. Baraza is a term that is used to describe any sitting area provided for meeting and conversation. Stereotypically, a baraza is a narrow, backless wooden bench leaned against an outside wall. often under an auning or on a verandah. In most cases the seats provided are portable and can be shifted around to accommodate additional interlocutors. Just as frequently, any stoop or low wall can serve as a place to sit. in which case the motility of the speakers, bodies. and not their chairs. creates the haraza in the act of sitting down for conversation. Occasionally baraza are fixed places, with permanent. often stone or cement, seats. but even the most fixed baraza accommodates whoever comes for conversation. Indeed. a widely spoken proverb recognizes the sociocentric character of these spaces: "Baraza ni watu, na watu ndiyo sisi" (The baraza 
is people, and we are the people, i.e., those who are gathered here, uttering this proverb). Conversation at the baraza thus reflexively constructs the space as well as the participants in the conversation as a baraza. In the course of social practice in Arusha, the baraza, to which people commonly refer and to which barbers refer when they characterize their shops as baraza, are the shaded benches set up in front of the open verandahs in most of the city's mosques. These are sites where senior men-and only men-gather before and after prayers, often sitting for hours at a time, finishing midmorning prayers and staying until midday prayers. They are almost always older men-certainly they were described to me as elders-who have the time to sit in extended conversation (to say nothing of having bodies that appreciate the rest).

The performative features of this shifting yet grounded place reveal important aspects of the barbershop, a place that can also be said to be, or to make, a baraza. This generational contrast and the religious identification add important dimensions to the gender asymmetry already described. Note that by drawing parallels between a rural site of women's activity and a rural and urban site for male elders, the kinyozi thickens the gender symbolism already discussed. As a point of generational contrast, the senior baraza as opposed to the junior kijiwe emphasizes, on the one hand, the young men's aspirations to propriety and social standing of the kind epitomized by men's talk at the mosque and male elders sacrificial authority, as well as the way that male elders' dominance over juniors incorporates an element of gender hierarchy. In effict. the baraza of junior men is the kijiwe of women. Again, the dynamic of inclusion and exclusion characteristic of these young men's efforts at belonging is thrown into relief. Moreover, comparing the barbershop to the baraza as well as kijiwe not only feminizes young men (which simultaneously demonstrates the authority of elders and bespeaks the young men's sense of their own displacement), it further compounds the ways in which the construction of masculine personhood is predicated on the exclusion of women. The urhan kijiwe, as a space occupied and enacted exclusively by men, highlights, I have suggested. the absence of women from this place of work. The transposition of this rural domain into an urban one as a gendered and hierarchical process is also confirmed in vernacular speech, in which kijiwe is rendered as kistone. This double voicing of Swahili and English (with the Swahili diminutive prefix) serves to situate the semantic value of the term in the urban community of speech. where English is (with wide disparities in competence) used and understood. Again, this highlights the transformation of the rural women $s$ zone into a fundamentally new kind of place when it is urbanized. I can only add that the emphatic utterance " $k i$-stone!" has a way of sounding aggressive and creates an exclusive community of speakers who can grasp the nuances of the metaphoric grindstone-urbanized, Anglicized, and inherently male-centered. What is more, if this masculinist appropriation of the kiliwe is also likened to the baraza, a characteristically Muslim and quintessentially urban (to say nothing of masculine) place, the implication is that the urbanization of a female locale as a male enclave is tantamount to the expulsion of women from urban sociality 
itself. My argument, then, is that by means of a spatial practice understood and performed at the intersection of the little stone and the baraza, young men in Arusha (or at least barbers and their clients) come to inhabit the experience of their own displacement (i.e., as junior men, subordinate to elders, scrambling to "find a life" in a tenuous informal economy) through their assertive erasure of women from their social field.

Let me immediately qualify this assertion. As I will discuss in greater detail below, these spatial practices do not consist solely in metaphorical aggrandizements about sitting around a barbershop. Rather, they are ramified through a host of related practices and discourse that constitute the sociality of the shops. Secondly, I hasten to point out that this absenting of women from urban sociality is plainly a fantasy, one that imaginatively enacts what we might call an aggressive thug realism (a term that both specifies its character on Arusha's streets and demonstrates how that specificity is embedded in a trans national image). For Arusha is a city in which women have long been active in exactly the kinds of commercial activities in which these young men are now struggling. As an enterprise, women's salons have a somewhat longer history than do men's barbershops; salon employees are older and have more experience (on the average) than barbers; and salon clients tend to have relatively greater means, as more young women move into service industry and office positions that expect (and provide the income to procure) good grooming. ${ }^{12}$ Further, the social interaction surrounding women's hair as opposed to men's has significantly deeper and more complex roots (forgive the pun). Women routinely care for one another's hair at home and at work; parents and older siblings tend to younger children's hair, while friends plait and comb each other's hair. often several times a week. Beyond these hair related endeavors, my (relatively incomplete) exploration of social organization in town suggests that households, especially those in the predominantly Muslim city center, are increasingly matrifocal. Many of the young men that I know well in Arusha live in homes under the authority of a mother or mother's sister; and many households are composed of persons related by matrilateral ties. ${ }^{13}$ This pattern is as true for relatively elite families, in which fathers and senior men regularly travel to Dar, the coast, Kenya, or even the Arabian Peninsula on business (and in many cases rarely return), as it is for poorer families, in which men hope to find work as waiters or porters in the safari industry or, increasingly, seek out work in the wildcat Tanzanite mines in the region. Under these conditions, illustrative of the widely lamented contemporary "crisis of masculinity" the world over (Comaroff and Comaroff 2000:307), the harbershop dream of women's subordination has to be seen as a form of symbolic violence that both denies women's legitimacy even as it bespeaks these young men's own subjugation.

This "thug realism" is-enacted and demonstrated in the most banal and self-evident ways every day in virtually every kinyozi in Arusha. It is not only that young unemployed (almost exclusively) men spend a great deal of time in these shops (Figure 2), it is also the case that much of the focus of their interaction turns on the boastful denigration of women. There is certainly nothing surprising 


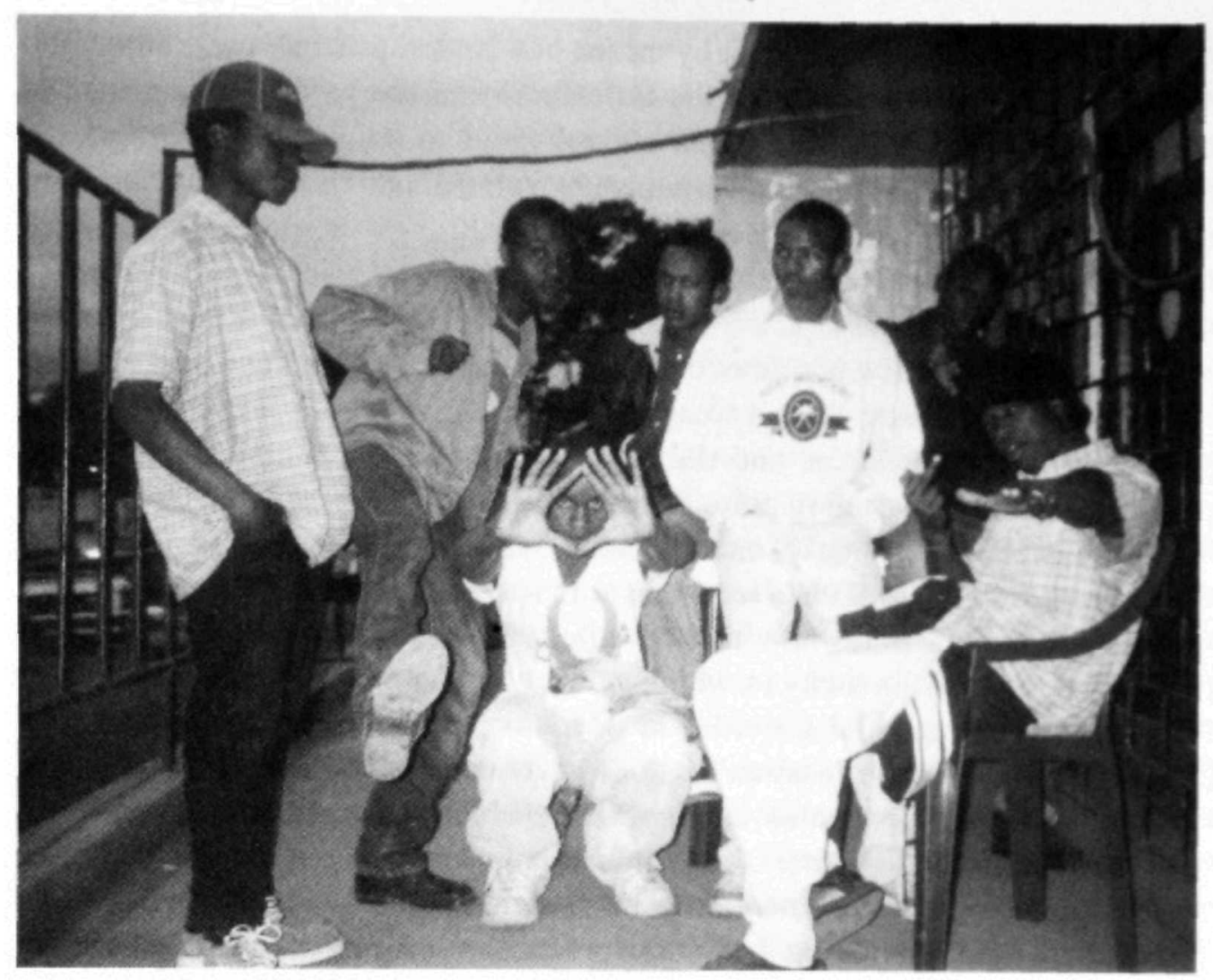

Figure 2

Thug realism.

about the kinds of encounters with women and antagonisms between men and women that these young men's conversations express. What is, perhaps, noteworthy are some of the ways that this gender exclusivism has begun to be organized and articulated in terms of a wider imagined world. In effect, the performance of masculinity becomes a switch-point in Arusha for articulating local social worlds as intrinsically grounded in a global context. As one example of this articulation. let me recount a conversation I once had about local clubs in Arusha (see also Weiss n.d.). One especially popular club was dismissed by my kinyozi friends as one they would never go to because the men who frequent this club are said to be only interested in attracting women. The patrons at this club, I was told, "would buy a beer for a girl before they would even buy one of their male friends a soda!" "Wasn't this OK?" I asked. "Not at all!" Even if a woman begged him, said one of these young men, he would only spend his money on his male friends. A woman. he continued, did not deserve the respect of your "boys," your "niggas" (both words he used in English) because "tupo mitaani ... sisi ... tuna-survive!" (We're in the streets ... us ... we survive!).

This forceful rebuke of my suggestion is noteworthy in a number of respects. Note that the social world defended is not only "tough" and "hard," demanding endurance and struggle as embodied and temporal qualities (discussed above); this 
world is also firmly rooted in spatial practice: "We're in the streets." This place - a moving hub amidst a mobile world-is one (like a baraza) in which the gathering together of people simultaneously constitutes the social relations in and as the locale they inhabit. The street-and the kinyozi that enfolds the street into itself and extends itself into the street-is not just a place where people live, it is a way of living. Note further that this characterization is implicitly a claim that derives force from its global underpinnings. "We survive" is an affirmation that is not only uttered in English, but is virtually a form of direct quotation derived from the verses of gangsta rappers. Indeed, many of the selfavowed "thugs" I know in Arusha have also described themselves to me as "street niggas" as a point of prideful independence derived, again, from the explicit ideological claims of African American hip-hop artists. Quite clearly, locating this contentious independence in spatial practice is also gendered; survival in the streets is not a viable attribute of women, at least in these young men's views. Further, these young men not only affirm their commitments to one another via their exclusion of women, they also evaluate the quality of those commitments in terms of relationships to women. That is, men measure their masculinity ielative to their attachments to women, casting praise and blame on those who demonstrate greater or lesser disdain for women.

\section{Embodied Fantasy}

I want to note briefly that this way of grounding masculinity as a local imagining of a global "realism" may also be deriving some of its force from what I can only tentatively describe as a renewed interest in Islam in Arusha. The same young men who listen to gangsta rap, tune in to Channel O (a South African music video cable network), read pornographic tabloids, and watch Jackie Chan movies are also "returning to Islam," as many of them put it. Most of the young men I knew in 1999 claimed to be Muslim, and while they professed belief in Almighty God, they rarely if ever went to prayers. In June of 2000 , a great many of these same young men were praying five times a day, reading Islamic literature imported from Kuwait, and engaging in conversations about the importance of faith in their lives. I have only begun to explore the meanings and implications of this "movement," if it can even he so characterized. I do feel, however, that there are certain standardized claims that a wide array of men, young and old. offered to me that contribute to this return to Islam. For every Muslim with whom I spoke, the force of Islam as a religion was not the strength of its faith (imani); even men I knew who prayed regularly told me that "faith was hard" and a source of much struggle. Rather, they claimed, Islam was critical to their lives (and should be to mine, a great many insisted) because Islam is true (kweli). The Koran in their view is not just a guide for living, it is a source of empirically verifiable knowledge. Indeed, the Koran is a guide for proper scientific investigation. its foreknown truths awaiting demonstration by research. ${ }^{14} \mathrm{~A}$ great many men further held that the surest "truth" of Islam and the clearest "proof" of Koranic validity was our own bodies. A male body is different from a female body. a fact reported in the Koran 
and self-evident to all. The superiority of the male body, and its similarity to the body of Muhammad in particular, is confirmed in the Koran and our own bodies thereby confirm Koranic truth. These kinds of bodily discourses inform a good deal of discussion of Islam. At the turn of the millennium, a number of young men I spoke with insisted that the signs of the end of the world were already apparent. Foremost among these signs, a claim known and asserted even by those who were skeptical of apocalyptic pronouncements, was the fact that women are said to exceed (kuzidi) men. "To exceed" is taken to mean every. thing from being more powerful than men, to women wearing pants, or to wives simply being older than their husbands.

In keeping with this embodied sexism, it is worth noting that one of the signs of male superiority is men's hair, or more specifically, men's beards. Beards - a topic quite relevant to passing time in a barbershop-were taken by many men who spoke with me to be a strong sign of divine preference for men. A man's beard showed his similarities to the prophet; Muhammad himself was endowed with a substantial beard as a sign of his election. The many hairs that make up a man's beard are each jinni (a tremendous blessing) but also a potential danger that only masculine strength can control.

This fascination with matters hirsute is telling. It also provides an entric into some central practices through which thug realism (with its conjunction of local and global imaginings) is directly enacted in barbershops and elsewhere in Arusha, that is to say, through haircuts. The question of what Mercer (1994) productively labels "Black Hair/Style Politics" is far too complex to address in any detail here, as is the broader anthropological question: "Why hair?" (Bcrg 1951; Derrett 1973; Leach 1958; Mageo 1994; Obeyesekere 1981: Stambach 1999; Synnott 1993; Turner 1980). What I can offer here is a sketch of the ways that current hair fashions, men's as well as women's. embody and display the broader dynamics of fantasy as a lived practice. I was first attracted to the study of barbershops by the fabulous iconic artwork that graces these shops. These images are usually immediately recognizable for the celebrities they depict, many (though not all) of whom have distinctive haircuts. Some of the most distinctive and pervasively illustrated haircuts (if I can call them that) are the renowned bald heads of Michael Jordan and Tupac Shakur (Figure 3). There is nothing intrinsically surprising about this of course; even bald heads need to be shaved. In fact, this point (discussed below) is more relevant than it might seem. What is at least a bit surprising is the fact that very few, if any, of the spectacular celebrity hairstyles painted on Arusha's kinyozi façades are actually selected as hairstyles by the men of Arusha. In fact. very few men shave their heads completely, although they do very much prefer extremcly short. closely cropped hair. Eiven fewer men choose to have designs. words. or patterns shaved into their hair. even though every shop.lists design (mtindo) and a complete head shaving (often listed as R Kelley after the R\&B performer) in its display of prices. Men in Arusha, it seems. recegnise the spectacular and the fashionable as created and effected among African American men, but the do not in any simple way imitate or even directly appropriate these styles. 


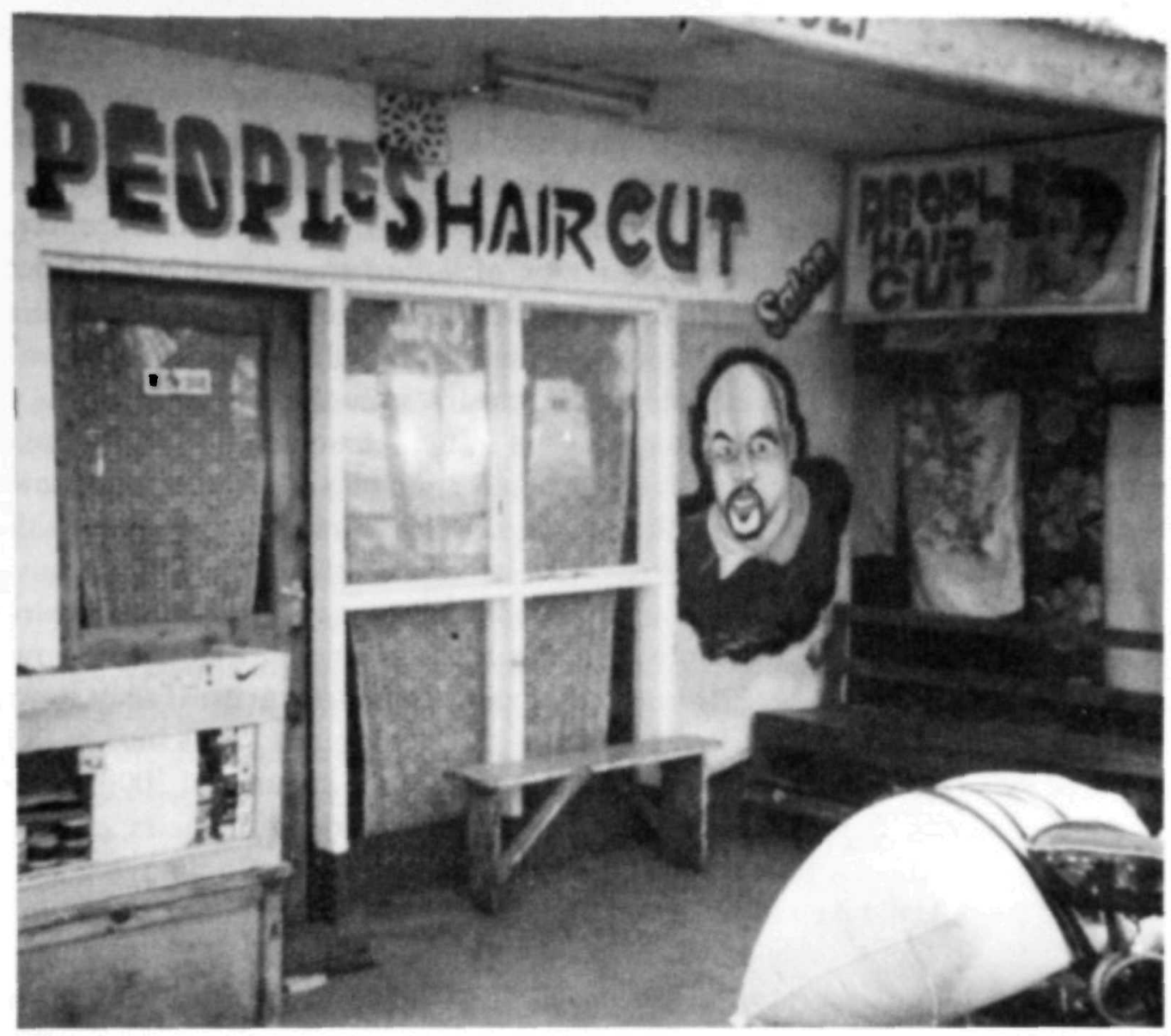

Figure 3

Bald Fantasy.

How might we account for this paradox? I asked many men and women if head shaving was still a practice of mourners in and around Arusha. and without exception everyone held that this was a very antiquated practice, one that was not only irrelevant to city life but hardly practiced in rural areas any longer. In any case this sacralization would hardly account for the celcbration of other people's bald pates. When I asked why so few men chose to shave their heads or "design" their hair, I was offered a few standardized explanations. First. some men told me that people in Arusha or "we Africans"-do not like to depart too much from tradition. Hairstyles "follow custom" (fuata mila), even as they "keep up with the times" (endelea na wakati). This tension is quite interesting. and conforms, I would argue, to the broader sociocultural emphasis on distancing already described. Just as Arusha's vinyozi publicize a landscape that marginalizes Arusha itself, so do the bodies of those who oc cupy this landscape remain excluded bodies. In my view, this distancing expresses both the displacement of those who spectacularize images that cannot reflect themselves, as well as a reflexive understanding of the necessity of this distance. For in order to show that one is fully in the know and grasps the profound significance of these ultimately most "real" of places, persons and 
styles, one needs to recognize a contrast between what is "here and now" and what provides the encompassing, overarching context that organizes the meaning of this "present." Conflating the distance by simply copying the ideal would reduce its magnificence and render it simply one place among many others-some "possible lives" no different from any other possibilities. Moreover, it would make these subjects' appreciation of these fantasy worlds indistinct from any other kind of knowledge or insight. Aspiring to participation in this imagined horizon apprehended as a truly fantastical reality is thus fundamentally predicated upon one's absence and exclusion from that world. ${ }^{15}$

While some men did express a tension in the relationship between "customary" and "timely" hair fashions, others offered a related but different vien of current hairstyles in Arusha. For many, wearing hairstyles associated with global hip-hop (bald heads and dreadlocks in particular) is simply dangerous. In fact, the dangers of hair are a regular topic of conversation in many barbershops. People told me (and more regularly told one another) stories of how guys who shaved their heads faced punishment from principals, if they were still in school, or were likely to be seen as threatening and suspicious in the eyes of the police. On the day before I left Arusha in the summer of 2000, threc or four different friends told me the story of how a friend of theirs, widel! known for his fabulous dreadlocks, had been misidentified as a mugging suspect by the police, taken in for interrogation and had all of his hair cut off. Indeed, "rastas," as they are known, are said to be regularly rousted by the police who worry that they project a bad image of the town to the Euro-American tourists. Again, local bodies are evaluated (and imagined) with respect to the place of Arusha as it is positioned in global terms. In each of these cases. hair-and especially men's hair-is a means of provocation as well as a medium of discipline. In these regards, it confirms the wider sociality of confrontation and "survival" that pervades life on the street and in its barbershops. To cut one's hair in a way that demonstrates one's command of the "thug realism" under discussion imposes a burden on the subject, requires that one face danger, and then endure in the face of these potential threats. Again. the global fantasy of participation in a "deterritorialized" order of strife and expulsion is lived in these concrete ways through which it is embodied and inhabited. Turmoil is never simply chaotic and incomprehensible; it rather acquires its sense as something unsettling and tangible through the ways it is (and must be) enacted.

Even at a much more mundane and less discursively elaborated level. hairstyles are performances (in the technical sense this term is used in much of cultural studies) that encapsulate these processes of embodying "thug realisn." While most men in Arusha do not directly invoke particular celebrity images when describing their haircuts or think much about why they do not cut their hair in one way or another, all of the young men I spoke with in Arusha could give some reason as for why they cut their hair as they did. I was interested in the popularity of closely cropped hair (a style that some. although only a few. actually labeled with respect to the fantastic as a "marine" cut. or more frequently, a "Tyson cut"), and almost without exception young men told me that 
they cut their hair short because it was simple: "I am too busy. I don't have time to comb out (kuchanua] my hair." "I travel often and with a short haircut I can just pour water on my head and I am clean." These are entirely commonplace explanations offered by men about their hair, which appear as matter-offact as can be. For men in Arusha, hair is simply a pragmatic concern, and it is cut in order to devote as little attention to it as possible; even rasta braids are said to be easy because they do not require daily care once they are grown. This very pragmatic attitude exemplifies exactly the qualities of the global fantasy so admired in Arusha. Such close cropping is a way of reducing the body to unadorned simplicity, refusing all indulgences and pleasures and showing indifference to appearances. Men who keep their hair cut short are avowedly treating their bodies as mere instruments of utility and so they abide by the logic of the realism they project (see also Wacquant [1998:333] on the prizefighters "instrumentalist conception of, and relation to, the body"). These short, "practical" haircuts display the qualities of "toughness" and "hardness" essential to "thug life," thereby demonstrating one's commitment to this world. In making such displays, these men also concretely show that the world is grueling and exhausting and permits of no extravagance. In effect, the most pragmatic and unremarkable of haircutting practices (emblematic of an unspoken habitus) offers a performative confirmation of the truth that reality as imagined and engaged holds in urban Arusha.

Of course, the extreme irony of this pragmatic attitude-and further proof that this "pragmatism" is as symbolic as it is instrumental-is the fact that it takes a good deal of time, effort, and even money to maintain this indifferent appearance. Many men in Arusha get their hair cut at least once a week: literally every customer I spoke with said they got their hair cut at least every other week which, even if an exaggeration, that shows an ideological allegiance to the value of short hair. Haircuts are cheap, and barbering wages are completely inadequate to maintain the multitude of vinyozi in town. Even so, a haircut once a week is an expense that only a select few in Arusha can actually afford: even a cheap haircut amounts to half a day's pay for most. Still, while a complete commitment to this corporeal aesthetic is expensive, the range of forms this aesthetic takes permits almost everyone, regardless of their resources, to participate if only on occasion and in modest ways. A haircut once a month, a shoeshine less frequently, perhaps a used knit hat. or baseball cap once a year, these are items that can be acquired by even those of very meager means. The contradictions of this fantasy-the fact that embodying "thug realism" depends on commodified forms which are increasingly available but relatively inaccessible - can be sustained in practice because they actually exemplify the organizing principles of this "realism. That is, these fantasies endure, even when one is not regularly able to procure all of these forms (as, indeed, most young, irregularly employed men and women are unable to do), because they permit the possibility of participation with minimal expenditures every so often. At the same time these meager purchases concretely demonstrate that one has only a 
partial command of this totality of fantastic goods-and this very partiality invokes the exclusion that permits the total fantasy to retain its alluring appeal.

I would add that the concern with using hair as an instrument of time-saving may be seen as plainly symbolic when we contrast men's haircuts with wo. men's hairstyles. Women's salons and styles are topics that demand as much consideration, if not more, as I have devoted to barbershops. Here, I only want to highlight some central points of comparison. If men are concerned with timesaving hair, then women are more interested in what we might call the timeliness of their hair. A great many women get their hair styled in Arusha for the purpose of a specific event: a job interview, a wedding celebration, a return to one's natal home. Indeed, the form of their hairstyles demand this temporal specificity, as the most popular styles are extremely ephemeral. On one occasion I remarked to a woman who owned a rather successful salon that the carefully teased and curled style a customer had just received could not possibly last more than two or three days. "Ha!" she said, "that hair won't last until tomorrow!" Perhaps the most popular contemporary style in Arusha, and one that demands professional treatment, is a teased up, massive curl. The curl is produced by relaxing one's hair with a petroleum gel, setting it in curlers for a quarter of an hour, then teasing out the hair and pinning it back in a curl that sweeps up high on the crown of the head, or occasionally is teased to the back in a curl pinned to run from the crown to the neck (see Figure 4 for exaggerated examples of these styles). The resulting style is called a bomba (pipe) for the size of the curl produced. This teased up curl is not only evanescent in contrast to the closely cropped hair of modern men's fashion, the form of the hair itself is massive and voluminous, again a direct counter to the neatly shorn, simple men's cut. A successful woman creates an appearance of timely and fleeting elegance, while a man projects indifference and endurance. Each is an embodied performance that sustains, in both its own form and in its gendered contrast, an alluring fantasy.

Displacement and rupture are all too apparent in Arusha today. They are ever-present anxieties in each area of town and the constant topic of conversation, especially in barbershops and salons. Barbershops seemed vital and boisterous, if constantly on the verge of collapse in the summer of 1999. By the following year, while still thick on the ground, they had lost more than a little of their luster. So many young men that I spoke to in Arusha in 2000 seemed to be hardening themselves to the limited prospects they faced and as they prepared to embark on some perilous course of action to "look for a life." The appeal (and dread) of Tanzanite mining (a form of wildcat mining, notorious for its exploitative abuse of labor, rudimentary technological means, and criminally dangerous work conditions, but also revered for the mythical instantaneous fortunes that have been accrued by miners) was much more apparent. ()thers said they knew someone who knew someone who could get them a green card in the chimerical African lottery for American work permits. These relatively new fantasies speak to the "millennial" reduction of value production to sheer speculation (Comaroff and Comaroff 2000:295). In a world where tomorrow is 


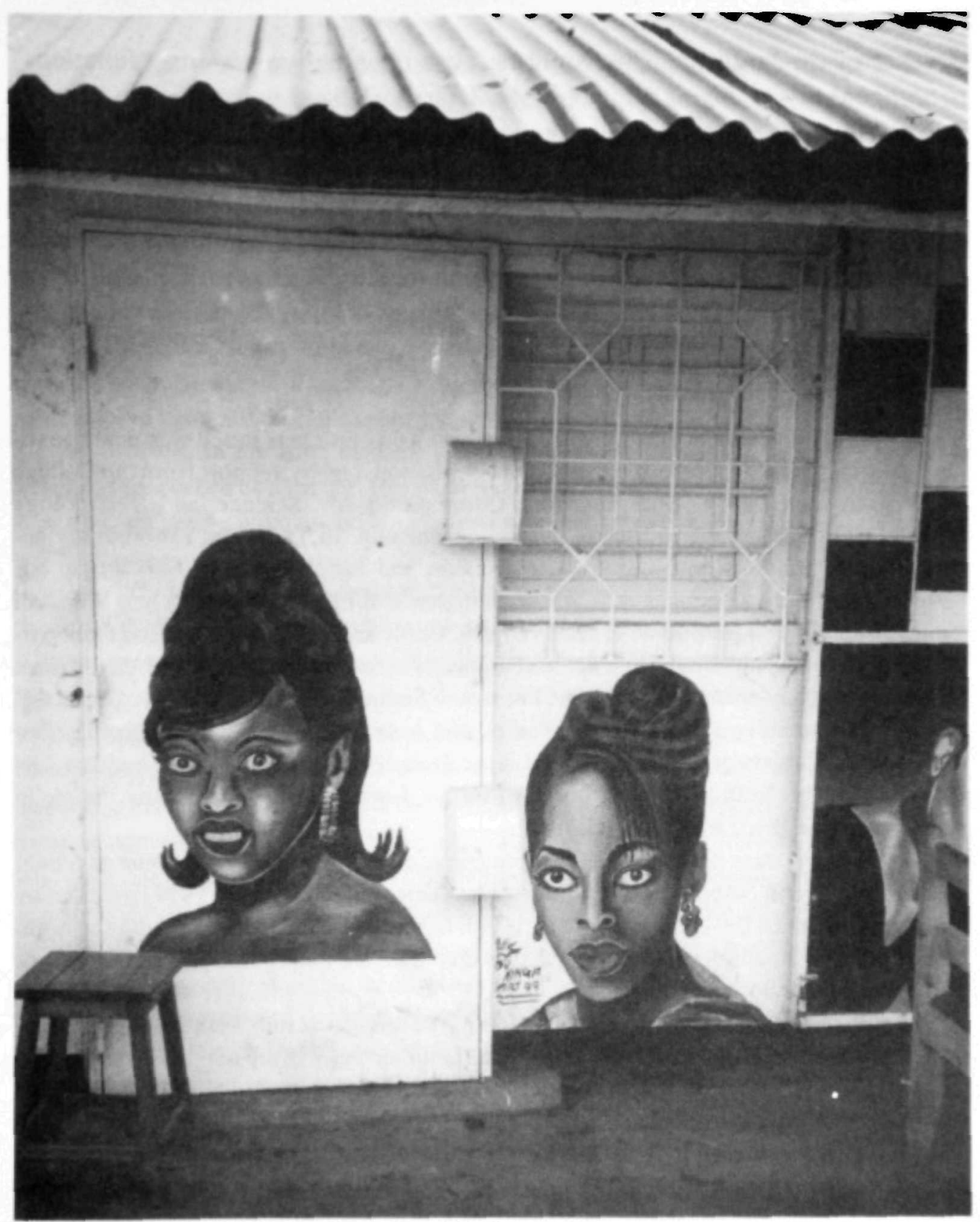

Figure 4

Bomba: timely, elegant coiffure.

only a dim prospect, striking it rich is hardly more fantastical than scraping hy As unmistakable as these processes are, the contention of this article has been that we are not well served by analytical attention to "the imagination" as something that only comes into existence under such condilions; or even, more dire in my view, that such rupture reduces social exrstence to fleeting and jumbled fantasies. Fantasies are real and they are poised, in Arusha at least, at precisely that intersection of global possibility and local limitation. Indeed, one of my main contentions here has been that marginality and exclusion are necessary 
features of the fantastic. This is not hecause imaginative practice "functions" to compensate for the inadequacies of a deterritorialized existence, but because locality itself is situated-and thus reconfigured-through its relationship to what is recognized and treated as a more potent, forceful and true world. It is this reconfiguring that depends upon distance and enactment, exclusion and inclusion. It is only by inhabiting these imagined worlds in the intimacy and concreteness of specific social frameworks that locality is produced, global forms are constituted, and fantasy is brought to life.

\section{Notes}

Acknowledgments. The research upon which this article is based was made possible by a small grant from the Wenner-Gren Foundation, and by support from the College of William and Mary. The Tanzania Commission for Science and Technology (COSTECH) enabled me to live and work in Tanzania. In Tanzania. 1 thoroughly enjoyed the tremendous hospitality of Jo Driessen and Judith Jackson. This article has benefited from the audiences at Mary Washington College and Franklin and .11:arshall College, for which I give special thanks to Eric Gable and Misty Bastian: and from participants in the Symposium on Current Perspectives in Anthropology and the African Studies Workshop conference on "The Politics of Social Reproduction in Neoliberal Africa." I am especially indebted to Bill Bissell and Amy Stambach for their helpful, criti. cal readings of this work. Special thanks to the three reviewers of this article and to Ann Anagnost for her enthusiastic support. Above all, I am grateful to the man! people in Arusha who made me welcome at kijiwe.

1. The literature on fantasy and the imagination is, of course. vast. Some excellent work in social and cultural anthropology (e.g., Allison 2000; Nelson 1999) inspired hy the work of Zizek (1997) among others, is emerging; its themes resonate with the argument I offer here, although I am less able to elucidate the psychoanalytical dimensions of the material under consideration

2. Certainly some have critiqued the notion of habitus as mindless social reproduction. In my own view, this overlooks the fact that subjectivity in the habitus is not created simply through repetition, but through the embodiment of dispositions. not the reenactment of a normative script.

3. The Term bongo in Arusha is, to my knowledge. used to refer to Dar es Salaam as a whole, although those more familiar with the capital's neighborhoods may be referring more specifically to Ubongo, a residential area that is home to many university faculty. My thanks go to Amy Stambach for pointing out this alternative possibility.

4. Consideration of the use of the term space in much critical theory and theories of popular culture can be useful compared with Swahili understandings of space as "opportunity," or "opening." This is a comparison I intend to pursue in future work.

5. By 2000 "Kosovo" marks had reverted to Nike swooshes and Fila dashes.

6. While I have detailed some of the spatial implications of this imagined marginality in terms of "distancing." the temporal features of marginality should also be noted. To recall the verses of Hard Blasterz Crew. "We're Behind!" is not simply an assertion of political weakness and inadequacy. it also expresses a sense of a temporal lag that many marginal communities experience. As Donham notes. "vernacular modernisms are often defined by the apparently simple fact that some actors view their societies as "behind' and therefore in need of a way of "catch up" " (1999:xv). From the perspective I am developing here, this temporal distancing complements the spatial forms already described. 
Fantasy is thus constituted as both a means of recognizing and aspiring towards that which "we' re behind," but the desire for that putative modernity and imagined future also depends upon the fact that it is not "our" present. I am indebted to a Cultural Anthropolog. reviewer for suggesting this point.

7. One of the more remarkable features of the shops is the way in which a strikingly narrow and similar set of images (African American rappers, basketball players, supermodels) can sustain a rather broad array of recognized styles. The forms themselves do not, in other words, dictate the fashions created with them.

8. These are clearly objectifying processes and they are absolutely central to the shops. These "displays" though, as I discuss below, are informed by a social practice rooted not in "images" but in a set of embodied dispositions.

9. In truth, in my time visiting over $\mathbf{5 0}$ barbershops in Arusha, I did know one woman who worked as a barber. Her work was a fact commented on as remarkable by all who met this young woman and her shop was widely known as the one where a woman was a barber.

10. While this is the immediate geographical context in which Arusha is situated. the town itself is not dominated by any single ethnic population. Indeed, barbers and their clients represent a vast array of regional and ethnic differences. As I describe below, many of the youth in the center of town are practicing Muslims and often identify with coastal communities from Dar es Salaam to Tanga to Zanzibar. There are also large Muslim populations from the interior, from cities like Tabora and Mwanza. There are also a number of shops owned by Christians, often Chagga, and sometimes Pare men and even, in some cases, women. Certain ethnicities, notably those Maasai and WaArusha who cultivate their ethnic identities and depend to a significant degree on a "traditional" appearance, virtually never frequent vinyozi. In short, no single ethnic community can be considered "representative" of barbershop life, nor do clients and barbers organize themselves according to ethnic or religious identifications.

11. I am indebted to Amy Stambach for pointing out this connection to me.

12. As Stambach (1999) and Tripp (1996) note, any number of NGOs and development agencies sponsored women-owned beauty salons as a means of targeting women's development in the 1990s.

13. See Askew (1999) for an excellent discussion of the variability of Swahili social organization in which she demonstrates that such matricentric ties have an enduring significance in Tanzania.

14. This experimental attitude is confirmed for many of the Muslims I know in reports from the Internet about scientific practice in the West inspired by readings of the Koran. Aside from the way the Internet is now contributing to the reformulation of Muslim communities, the internet as a technological achievement is also given legitimacy by this attitude.

15. Local styles of dress, especially the appropriation of mitumba, or used clo:hing, is characterized by a similar dynamic. In spite of the fact that young men and women in Arusha are quite familiar with the most popular American and European brands of clothing-especially sportswear such as Nike and Reebok. Fila and FuBu-and can frequently purchase cast-off examples of these brands, many people remain convinced that the clothes available to them are only pale imitations of the "real" brands that (as they imagine) pervade Euro-American markets. 


\section{References Cited}

Abu-Lughod, Lila

1997 The Interpretation of Culture(s) after Television. Representations 59:109-134

Allison. Anne

2000 Permitted and Prohibited Desires: Mothers, Comics, and Censorship in Japan

Berkeley: University of California Press.

Anderson. Benedict

1983 Imagined Communities: Reflections on the Origins and Spread of National-

ism. London: Verso.

Appadurai. Arjun

1991 Global Ethnoscapes: Notes and Queries for a Transnational Anthropology. In

Recapturing Anthropology: Working in the Present. Richard G. Fox. ed. Pp. 191-

210. Santa Fe, NM: School of American Research Press.

1996 Modernity at Large: Anthropological Explorations of Globalization. Minneapolis: University of Minnesota Press.

Askew, Kelly M.

1999 Female Circles and Male Lines: Gender Dynamics along the Swahili Coas

Africa Today 46(3,4):67-102.

Baroin, Catherine

1996 Religious Conflict in 1990-1993 among the Rwa: Secession in a Lutheran

Diocese in Northern Tanzania. African Affairs 95(381):529-5.54

Bayart, Jean-François

1996 L’Illusion Identitaire. Paris: Fayard.

Beidelman, T. O.

1997 The Cool Knife. Washington, DC: Smithsonian.

Berg, Charles

1951 The Unconscious Significance of Hair. London: Allen and Unwin.

Carrier, James G., and Daniel Miller, eds.

1998 Virtualism: A New Political Economy. Oxford: Berg.

Comaroff, Jean

1985 Body of Power, Spirit of Resistance: The Culture and History of a South Afri-

can People. Chicago: University of Chicago Press.

Comaroff. Jean, and John L. Comaroff

2000 Millennial Capitalism: First Thoughts on a Second Coming. Public ( ulture 12(2):291-34.3.

Comaroff, John L.. and Jean Comaroff

1999a Civil Society and the Political Imagination in Africa. ('hicago: Universlly of Chicago Press.

1999b Occult Economies and the Violence of Abstraction: Notes Irom the South Af.

rican Postcolony. American Ethnologist 26(2):279-301.

Derrett, J.

197.3 Religious Hair. Man. n.s.. 8:100-103.

Donham, Donald

1999 Marxist Modern: An Ethnographic History of the Fthiopian Revolution.

Berkeley: University of California Press.

Ferguson, James

1999 Expectations of Modernity: Myths and Meanings of Urhan life on the Zam-

bian Copperbelt. Berkeley: University of California Press. 


\section{Foster, Robert}

1999 Melanesianist Anthropology in the Era of Globalization. The Contemporary

Pacific 11(1):140.

Gupta, Akhil, and James Ferguson

1997 Beyond "Culture": Space, Identity and the Politics of Difference. In Culture,

Power, Place. Akhil Gupta and James Ferguson, eds. Pp. 33-51. Durham, NC: Duke University Press.

\section{Gusterson, Hugh}

1999 Nuclear Weapons and the Other in the Western Imagination. Cultural Anthropology 14(1):111-143.

\section{Hannerz, Ulf}

1996 The Local and the Global: Continuity and Change. In Transnational Connections: Culture, People, Places. Ulf Hannerz, ed. Pp. 17-29. New York: Routledge.

Leach, Edmund

1958 Magical Hair. Journal of the Royal Anthropological Institute 88:147-164.

Lefebvre, Henri

1991 The Production of Space. D. N. Smith, trans. Cambridge, MA: Blackwell.

Mageo, Jeannette Marie

1994 Hairdos and Don'ts: Hair Symbolism and Sexual History in Samoa. MAN 29(2):407-433.

Martin, Emily

1998 Flexible Bodies. New York: Basic Books.

\section{Mercer, Kobena}

1994 Black Hair/Style Politics. In Welcome to the Jungle: New Positions in Black

Cultural Studies. Kobena Mercer, ed. Pp. 97-128. New York: Routledge.

Merleau-Ponty, Maurice

1962 The Phenomenology of Perception. London: Routledge and Kegan Paul.

Munn, Nancy

1990 Constructing Regional Worlds in Experience: Kula Exchange, Witchcraft and Gawan Local Events. Man, n.s., 25(1):1-17.

1996 Excluded Spaces: The Figure in the Australian Aboriginal Landscape. Critical Inquiry 22(3):446-466.

Nelson, Diane

1999 A Finger in the Wound: Body Politics in Quincentennial Guatemala. Berkeley:

University of California Press.

Obeyesekere, Gananath

1981 Medusa's Hair: An Essay on Personal Symbols and Religious Experience.

Chicago: University of Chicago Press.

Remes. Peter

1999 Global Popular Music and Changing Awareness of Urban Tanzanian Youth.

Yearbook for Traditional Music 31:1-26.

Sahlins, Marshall

1999 Two or Three Things that I Know about Culture. Journal of the Royal Anthropological Institute 5(3):399-422.

Setel, Philip

2000 A Plague of Paradoxes: AIDS, Culture and Demography in Northern Tanzania. Chicago: University of Chicago Press. 


\section{Stambach, Amy}

1999 Curl Up and Dye: Civil Society and the Fashion-Minded Citizen. In Civil Society and the Political Imagination in Africa: Critical Perspectives. John L. Comaroff and Jean Comaroff, eds. Pp. 251-266. Chicago: University of ('hicago Press 2000 Lessons From Mount Kilimanjaro: Schooling, Community, and Gender in East Africa. New York: Routledge.

Synnott. Anthony

1993 The Body Social. London: Routledge.

Tripp, Aili Mari

1996 Changing the Rules: The Politics of Liberalization and the Urban Informal Economy in Tanzania. Berkeley: University of California Press.

Turner. Terence

1980 The Social Skin. In Not Work Alone: A Cross-Cultural View of Activities Superfluous to Survival. Jeremy Cherfas and Roger Lewin. eds. Pp. 112-140. Beverly Hills, CA: Sage.

1993 Anthropology and Multiculturalism: What is Anthropology that Multiculturalists Should be Mindful of It? Cultural Anthropology 8(4):411-429.

Turner, Victor

1967 The Forest of Symbols. Ithaca, NY: Cornell University Press.

Wacquant, Loïc

1998 The Prizefighter's Three Bodies. Ethnos 63(3):325-352.

Weiss, Brad

N.d. The Barber in Pain. Unpublished MS. Department of Anthropology. College of William and Mary.

Zizek, Slavoj

1997 The Plague of Fantasies. London: Verso Books. 